\title{
OBJECTIVE AND SUBJECTIVE INDIC ATORS: EFFECTS OF SCALE DISCORDANCE ON INTERRELATIONSHIPS
}

\author{
(Received 6 December, 1978)
}

\begin{abstract}
Researchers in the social indicator movement are increasingly aware of the value of obtaining both subjective and objective measures. At the same time there is a recognition of the need to understand relationships between the types of measures. Studies utilizing both subjective and objective measures indicate that while relationships between them exist, relationships are often not strong. This paper suggests several explanations for such imperfect relationships. One is scale discordance, a term used to recognize that the territorial base of an individual's subjective evaluation may not coincide with the boundaries of the unites used for the collection of objective data. Using data from a metropolitan area study, relationships between objective measures of crime and respondents' feelings of safety are examined for people whose perceptions of neighborhoods vary in size. The hypothesis that the relationship between the objective and subjective measures is stronger among individuals whose view of neighborhood size is in line with the relatively large territorial base for objective crime statistics is tested and found to be correct. Implications of the findings for research and policy making are discussed.
\end{abstract}

\section{INTRODUCTION}

There is growing acceptance among policymakers and many in the social science community that two quite distinctive types of social indicators are appropriate for measuring societal and individual well-being. One type has been generally referred to 'objective' and has been characterized by hard measures describing the environments within which people live and work. Conditions can deal with health, crime, taxes, education, leisure time, voting behavior, housing, and any number of other aspects of peoples' lives. Typical of studies using objective indicators is Liu's report on conditions in metropolitan areas of the U.S. (Liu, 1975) and the Urban Institute's comparison of American cities (Flax, 1972).

The second type of indicator of societal or individual well-being is commonly referred to as 'subjective' and is intended to describe the ways people perceive and evaluate conditions existing around them. Pioneering work with subjective social indicators has been reported in Gurin et al. (1965) and Bradburn (1969) while more recent activities based on national survey data 
have been conducted by Campbell et al. (1976) and Andrews and Withey (1976).

Most social indicator work has focused on either objective or subjective measures. However, a limited number of efforts have been made in recent years to collect both types of indicators within the context of a single study. Justification for such efforts centers on the belief that one type of indicator can contribute to the interpretation of the other. For example, an understanding of the meaning of objective health statistics would be facilitated by complementary data covering people's perceptions of their own health, the care they receive, or the health services available to them. Similarly, it could be argued that people's evaluations of various public services would take on greater meaning for both the policy maker and the researcher when they are viewed in light of the actual performance of those services.

More recently, the extent to which subjective and objective indicators of the same phenomenon or condition correspond with each other has been reported in the literature. Of particular interest is the fact that the extent to which there is agreement varies considerably from one condition to another. In some instances, relationships between objective and subjective measures are strong while in others, they are quite weak or nonexistant. For example, Campbell et al. (1976) in their national quality of life study found a very high correlation $(r=0.84)$ between the perceived racial composition of the respondents' neighborhoods and objective measures of population composition for those areas. The same study also compared the respondents' assessments of a number of neighborhood characteristics with the independent assessments of the interviewers. In one sense, this is the comparison of two subjective evaluations, although the researchers considered these ratings to be 'objective' in the sense that they were not made by the respondents whose assessments and satisfactions they were trying to predict (1976, p. 246). Interviewer and respondent assessments were found to be highly correlated for items such as the number of trees in a neighborhood, or the level of traffic flow, but lower correlations were found on more abstract evaluations such as neighborhood friendliness (1976, p. 247).

Appleyard and Lintell's study of environmental quality of city San Francisco streets (1972) showed clear relationships between subjective evaluations of the neighborhood and objective measures of traffic flow and noise. In addition, differences in objective conditions were related to differences in levels of social interaction between neighbors in different noise and 
traffic environments, and to the sense of territoriality expressed by respondents.

In another context, Marans and his colleagues (1976) examined relationships between three separate measures of lake water quality and the evaluations of that quality by residents living along waterfronts in northern Michigan and found correlations ranging from 0.01 to 0.76 .

In two urban studies, Schuman and Gruenberg (1974) and Stipak (1977) reported relationships! between the provision of urban services and citizen evaluations of those services. Schuman and Gruenberg found that the correlations between subjective evaluations and objective characteristics were "...all modest in size and some are trivial" (1976, p. 377) while Stipak's analysis showed that only in extreme cases to differences in service provision affect evaluations of those services. "Not only are respondents ignorant of the basic facts of service provision in their cities, but also the service evaluations they provide have little to do with the quality of those services" (1977, p. 50).

Finally, Schneider's study of the quality of life in large American cities (1975) reported wide discrepancies between objective and subjective indicators of the same condition. Schneider found fairly small differences between residents in the different cities in his study in terms of their subjective evaluation or satisfaction with a number of domains, despite the fact that there were large differences between the cities in terms of objective indicators. "In short, there appears to be no evidence at all that, as measured by currently popular indicators, the objective social conditions of cities has (sic) any relationship with the levels of subjective life quality of their citizens" (Schneider, 1975, p. 505).

\section{REASONS FOR IMPERFECT RELATIONSHIPS BETWEEN}

OBJECTIVE AND SUBJECTIVE INDICATORS

It is clear from the literature that there is no direct and perfect correlation between objective indicators and the individual perception of conditions related to any particular domain. However, given the nature of perception it is not surprising that there should be divergence between perceived conditions and conditions measured by means of objective indicators. For example, Tajfel sees the whole field of social perception as being "...generally concerned with the effects of social and cultural factors on man's cognitive structuring of his physical and social environment" (1968, p. 567). 
Many factors intervene between the objective world and an individual's perception of it. These include personal and social characteristics such as age, income, education, and race which may act as filters to distort objective conditions. Thus, individual perceptions transform what is initially seen as a universal objective situation into a highly individualistic interpretation of that condition.

Individual experience is also a key factor which will affect the perception of a specific domain. For example, the experience of being a victim of a crime is likely to have a deep and lasting effect on the individual's perception of safety in his home or neighborhood, irrespective of the level of crime there as measured by objective indices. Another factor which may be important in objective-subjective divergence is the aspiration level, or expectations of the individual (Campbell et al., 1976). Campbell et al., suggest that this factor is apt to be important in explaining, say, the relatively high satisfaction of an individual whose objective situation is consensually poor (1976, p. 482).

A factor related to the concept of aspiration levels is the individual's standard of comparison against which objective conditions are measured. These standards of comparison are partly a reflection of an individual's experience and partly reflect the social and cultural values and attitudes of the society or the community in which an individual lives. In discussing the relationship between objective and subjective well-being, d'Iribarne notes that "...the link between physical situation and well-being is not a 'natural' link independent of society, but is liable to be heavily affected by 'cultural' phenomena which will depend on several of the characteristics of the society in which he lives" $(1974$, p. 37). The effect of these is likely to be most pronounced at the macro-scale, when comparisons are made of the evaluations of specific domains by populations in different countries with different cultural and social environments. However, it is also reasonable to assume that at the micro-scale different social groups within, say, a metropolitan region, operate within different physical, social, and cultural environments which will affect evaluations of well-being.

The concept of the influence of an individual's environment ties in with the notion of accommodation discussed by Campbell et al. (1976) as another factor which may affect objective-subjective relationships. One manifestation of this concept is that, in a fixed situation, an individual's satisfaction with a condition may increase over time by accommodation to that situation. Campbell et al., feel that this concept is helpful in understanding why people 
trapped semi-permanently in poor objective situations express relatively high levels of satisfaction with their conditions (1976, p. 485).

In addition to these factors which are common to the perception of many phenomena, perception of the conditions measured by social indicators also poses the problem of scale discordance. 'Scale discordance' is used here as a term to recognize that while objective social indicators are collected for well-defined territorial units (whether the data be for a nation, a city, a census tract, or a school district) it is unlikely that the territorial base of an individual's perception will coincide exactly with the boundaries of the administrative unit used for the collection of objective data. Schneider has recognized this as a likely source of discrepancy between objective and subjective evaluations of social conditions in American cities. He notes the possibility that objective conditions within "...areas that individuals are more familiar with, may impinge more on subjective evaluations of life than do the conditions of the city as a whole" (1975, p. 506).

In fact, the scale discordance factor may affect all domains of well-being that incorporate a territorial component, including general notions of neighborhood satisfaction.

\section{DATA AND ANALYSIS}

Of the factors which might affect the relationship between objective and subjective evaluations, this paper focuses specifically on the influence of scale discordance. To do this requires not only objective and subjective measures of the same condition, but also a measure of the scale at which individuals perceive their neighborhood. A study by The University of Michigan's Institute for Social Research on the quality of life in the Detroit area provided these three types of variables. This paper uses crime statistics and feelings of safety as the objective and subjective measures to be compared. The Detroit study also collected information on the size of the neighborhood perceived by respondents in the survey, and this information is used here to examine the influence of scale discordance. Within the Detroit sample, there was considerable territorial variation in the concept of neighborhood - from an area covering only five or six houses to an area of more than one square mile (Table I).

Overall, objective measures of crime and the respondents' feelings of safety reveal only a modest correlation (see Table II). ${ }^{1}$ Moreover, the 
TABLE I

Perceived scale of neighborhood ${ }^{\text {a }}$

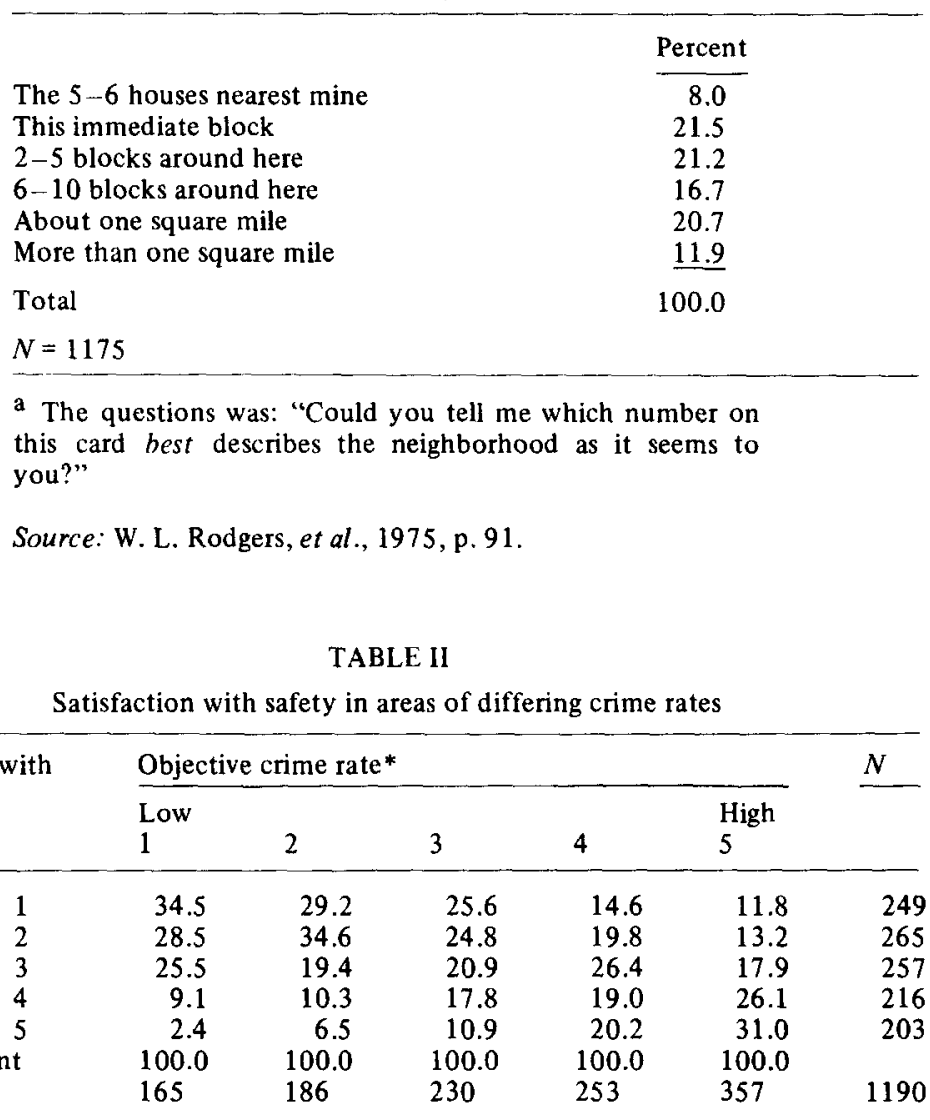

Tau B $=0.30$

* Number of crimes per 100000 population.

data reveal that there are proportionately more people who live in areas with high crime rates who feel relatively satisfied with safety in their areas, than there are people in low crime areas who are dissatisfied with safety.

In this context of this study's focus on scale discordance, it was hypothesized that there would be a greater correspondence between observed crime data and subjective feelings of safety for those respondents who viewed their neighborhood as a large territorial unit. We expected this because crime 
statistics were collected for political or administrative units which embraced considerably larger areas than the neighborhood size upon which many of the respondents based their perceptions of safety, neighborhood satisfaction and the like. ${ }^{2}$

The hypothesis was tested by incorporating the scale of neighborhood variables into a model which sought to explain variation in subjective safety (as a dependent variable). Specifically, it was hypothesized that the greater correspondence between objective and subjective measures for macro-neighborhood perceivers would result in the model accounting for a greater proportion of the variance in the dependent variable than it would for people who perceived the neighborhood as a small unit.

To provide a comparative benchmark for the analyses for groups with differing perceptions of neighborhood scale, two models were examined to determine what proportion of the variation in subjective feelings of safety could be explained by a number of predictor variables. ${ }^{3}$ The predictor or independent variables were three personal characteristics of the respondents, plus the measure of objective crime associated with the respondents' neighborhoods. It should be noted that these models were not intended to explain as much as possible of the variance in subjective safety, but rather to provide a mechanism for examining the possible influence of the scale discordance factor on the objective-subjective relationship under consideration.

TABLE III

Prediction of satisfaction with safety by personal characteristics and objective crime rates (multiple classification analy sis)

\begin{tabular}{llll}
\hline & $\begin{array}{l}\text { Eta } \\
\text { coefficient }\end{array}$ & \multicolumn{3}{l}{ Beta coefficient (ranking of importance) } \\
\cline { 4 - 4 } & & $\begin{array}{l}\text { I } \\
\text { Personal charac- } \\
\text { teristics only }\end{array}$ & $\begin{array}{l}\text { II } \\
\begin{array}{l}\text { Personal charac- } \\
\text { teristics and } \\
\text { objective crime }\end{array}\end{array}$ \\
\hline $\begin{array}{l}\text { Personal characteristics } \\
\text { Length of residence in city }\end{array}$ & 0.17 & $0.24(1)$ & $0.08(4)$ \\
$\begin{array}{l}\text { Age of respondent } \\
\text { Number of years schooling }\end{array}$ & 0.10 & $0.20(2)$ & $0.14(2)$ \\
$\begin{array}{l}\text { Objective crime } \\
\text { Index of crime rate }\end{array}$ & 0.12 & $0.16(3)$ & $0.13(3)$ \\
$\begin{array}{l}\text { Explained variance } \\
\text { (adjusted multiple } R^{2} \text { ) }\end{array}$ & & & $0.37(1)$ \\
Number of respondents $=1170$ & $6.4 \%$ & $17.5 \%$ \\
\hline
\end{tabular}


Table III shows the ability of the independent variables in the two models to predict subjective feelings of safety using multiple classification analysis (Andrews et al., 1973). In the first model, simultaneous consideration of the three background variables explains only 6.4 percent of the variance in subjective safety. In the second model, an objective measure of crime in the respondent's home area was introduced. The inclusion of this variable, together with the variables in the first model, suggests that an individual's feeling of safety in his area is related not only to the set of personal characteristics which might affect perception, but also to the actual levels of crime that prevail there.

The summary statistics show that the eta coefficient for the objective crime index is considerably higher than for any other predictor variables in the model. Moreover, the beta coefficient indicates that this is the most important variable in the model for explaining variation in subjective feelings of safety. In conjunction with the three personal characteristics, the objective crime variable accounts for 17.5 percent of the variance in subjective safety, with a marginal contribution for objective safety of 11.1 percent over the explanatory power of the three personal characteristics alone. ${ }^{4}$ In addition to providing a benchmark for comparing the effects of scale discordance, the relatively low levels of variance explained by the models also highlight the complexities of objective-subjective relationships.

\section{EFFECTS OF PERCEIVED SIZE OF NEIGHBORHOOD}

When the analysis of Model II is repeated separately for two groups differing in perceived neighborhood size there is considerable difference in the proportion of the variance explained. (See Table IV). For the group identifying their neighborhood as a relatively small area (10 blocks or less) the model explains 15.0 percent of the variance in feelings of safety. However, for those who view their neighborhood as a larger unit (one square mile or more) 23.5 percent of the variance in subjective safety was explained by the same set of predictor variables. This is considerably higher than the 17.5 percent explained by the model for the total sample without consideration of the scale discordance factor.

The simple bivariate relationship between the objective crime variable and the subjective measure is higher for the large neighborhood group (Eta = 0.46) than it is for those who view their neighborhood as relatively small 


\section{TABLE IV}

Prediction of satisfaction with safety by personal characteristics and objective crime rates for small and large neighborhood groups (multiple classification analysis)

\begin{tabular}{|c|c|c|c|}
\hline & \multicolumn{3}{|c|}{ SMALL NEIGHBORHOOD GROUP } \\
\hline & \multirow{2}{*}{$\begin{array}{l}\text { Eta } \\
\text { coefficient }\end{array}$} & \multicolumn{2}{|c|}{ Beta coefficient (ranking of importance) } \\
\hline & & $\begin{array}{l}\text { I } \\
\text { Personal charac- } \\
\text { teristics only }\end{array}$ & $\begin{array}{l}\text { II } \\
\text { Personal charac- } \\
\text { teristics and } \\
\text { objective crime }\end{array}$ \\
\hline $\begin{array}{l}\text { Personal characteristics } \\
\text { Length of residence in city } \\
\text { Age of respondent } \\
\text { Number of years schooling }\end{array}$ & $\begin{array}{l}0.16 \\
0.08 \\
0.11\end{array}$ & $\begin{array}{l}0.22(1) \\
0.21(2) \\
0.18(3)\end{array}$ & $\begin{array}{l}0.08(4) \\
0.15(3) \\
0.15(2)\end{array}$ \\
\hline \multirow[t]{2}{*}{$\begin{array}{l}\text { Objective crime } \\
\text { Index crime rate } \\
\text { Explained variance } \\
\text { (adjusted Multiple } R^{2} \text { ) } \\
\text { Number of respondents }=761\end{array}$} & 0.38 & $5.5 \%$ & $\begin{array}{l}0.35(1) \\
15.0 \%\end{array}$ \\
\hline & \multicolumn{3}{|c|}{ LARGE NEIGHBORHOOD GROUP } \\
\hline $\begin{array}{l}\text { Personal characteristics } \\
\text { Length of residence in city } \\
\text { Age of respondent } \\
\text { Number of years schooling }\end{array}$ & $\begin{array}{l}0.18 \\
0.09 \\
0.14\end{array}$ & $\begin{array}{l}0.29(1) \\
0.24(3) \\
0.26(2)\end{array}$ & $\begin{array}{l}0.09(4) \\
0.19(3) \\
0.21(2)\end{array}$ \\
\hline $\begin{array}{l}\text { Objective crime } \\
\text { Index crime rate } \\
\text { Explained variance } \\
\text { (adjusted multiple } R^{2} \text { ) } \\
\text { Number of respondents }=372\end{array}$ & 0.46 & $9.1 \%$ & $\begin{array}{l}0.44(1) \\
23.5 \%\end{array}$ \\
\hline
\end{tabular}

$(E t a=0.38)$. This confirms the hypothesis that there would be a greater correlation between the objective and subjective measures for those who view their neighborhood as a large territorial unit. The greater correlation between the objective and subjective measures for the large neighborhood group is reflected in the different outcomes of the models with a 14.4 percent marginal contribution from objective crime for the large neighborhood group compared to only 9.5 percent for the small neighborhood group.

The divergence between the perceived size of the neighborhood and the size of the areal unit upon which territorial social indicators are collected (scale discordance) is an important factor, at least within the context of this analysis. By controlling for scale discordance, substantial differences emerge 
between the two groups in the correlation between objective and subjective indicators, as well as in the multivariate explanation of the variation in subjective feelings of safety.

\section{SCALE DISCORDANCE IN CONJUNCTION WITH OTHER}

INTERVENING VARIABLES

The preceding analysis demonstrates that scale discordance is one factor, previously unexplored, which can modify relationships between objective conditions and peoples' perceptions of them. It is, however, only one of a number of factors which may influence the objective-subjective relationship. The literature review and discussion outlined earlier suggested that not only may personal and environmental factors affect the objective-subjective relationship, but there may be increasing divergence between the two measures if individuals exposed to a fixed situation gradually accommodate to the prevailing conditions. If such accommodation takes place, satisfaction may rise without commensurate improvement in the corresponding objective condition (Campbell et al., 1976, p. 485).

To gain further insight into the relevance of the scale discordance factor, it is pertinent to explore its influence in conjunction with other factors which intervene in the objective-subjective relationship. To this end, it can be argued that disaggregation of the sample according to race is one way of encapsulating the variations within the Detroit area of neighborhood conditions, as well as personal-social characteristics together with the possible influence of accommodation to areas of high crime. The rationale for disaggregation by race is as follows. In common with other U.S. metropolitan areas, crime rates in the Detroit region display a market spatial pattern with higher crime rates in the inner city and lower levels of crime in the outer suburbs. This urban core-periphery pattern of crime correlates more strongly with the distribution of black and white residents than with any other characteristic of the population. Table $\mathrm{V}$ shows sharp differences between the two groups in terms of their exposure to different levels of crime. More than 8 out of every 10 blacks in the sample were living in areas with the highest crime rate, whereas only one in 10 of the whites were exposed to the same crime environments.

It is also true that, through discrimination and differential access to housing and employment, blacks face far greater constraints than do whites 


\section{TABLE V}

Proportions of white and black respondents living in areas of differing crime rates

\begin{tabular}{ccr}
\hline Objective crime rate & Whites & Blacks \\
\hline Low 1 & 18.6 & - \\
2 & 20.7 & 1.0 \\
3 & 25.0 & 2.8 \\
4 & 24.8 & 10.0 \\
High 5 & 10.9 & $\frac{86.2}{100.0}$ \\
Total (percent) & 100.0 & 100 \\
Number of respondents & 880 & 290 \\
\hline
\end{tabular}

in attempting to move from areas of high crime. As many blacks are exposed to a relatively fixed situation of high crime (vis-a-vis whites) it is possible that blacks have adapted to, or accommodated this situation. Consequently, their levels of satisfaction with safety may have risen above those which might be expected given their residence in areas of high crime.

If the hypothesis is true that urban blacks have adapted somewhat to the high crime environments in which many of them live, then there should be a weaker correlation between objective and subjective safety for blacks than there is for whites. Tables VI and VII show that this hypothesis is supported by the Detroit data. Not only is the association between the two measures much weaker for the blacks than for the whites $(\mathrm{Tau}=0.11$ versus $\mathrm{Tau}=$ 0.28 ) but the bivariate distribution for blacks reinforces the suggestion of

TABLE VI

Satisfaction with safety in areas of differing crime rates: blacks

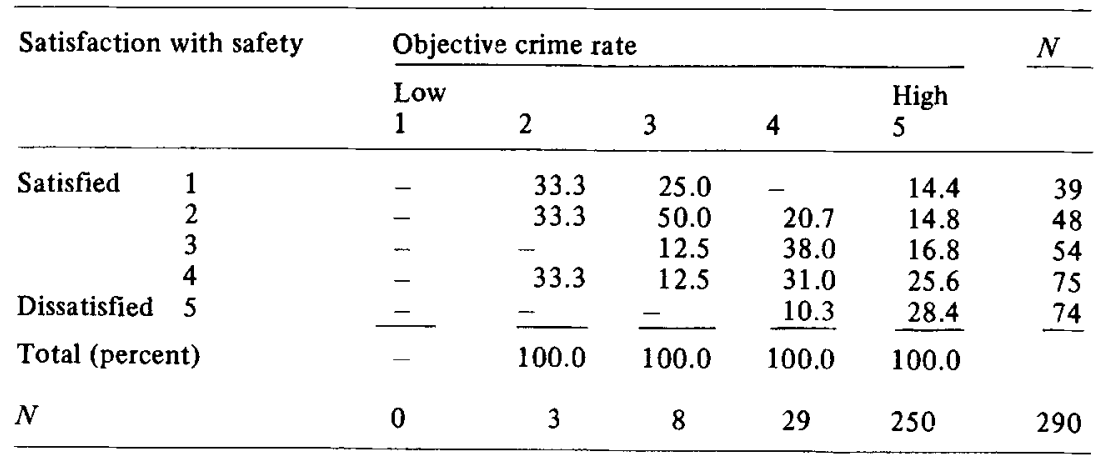

Tau $B=0.11$ 
TABLE VII

Satisfaction with safety in areas of differing crime rates: whites

\begin{tabular}{|c|c|c|c|c|c|c|c|}
\hline \multirow{2}{*}{\multicolumn{2}{|c|}{ Satisfaction with safety }} & \multicolumn{5}{|c|}{ Objective crime rate } & \multirow[t]{2}{*}{$N$} \\
\hline & & $\begin{array}{l}\text { Low } \\
1\end{array}$ & 2 & 3 & 4 & $\begin{array}{l}\text { High } \\
5\end{array}$ & \\
\hline $\begin{array}{l}\text { Satisfied } \\
\text { Dissatisfied }\end{array}$ & $\begin{array}{l}1 \\
2 \\
3 \\
4 \\
5\end{array}$ & $\begin{array}{r}34.8 \\
28.7 \\
25.6 \\
8.5 \\
2.4 \\
\end{array}$ & $\begin{array}{r}29.1 \\
34.6 \\
19.8 \\
9.9 \\
6.6 \\
\end{array}$ & $\begin{array}{l}25.9 \\
24.1 \\
20.4 \\
18.2 \\
11.4 \\
\end{array}$ & $\begin{array}{l}16.1 \\
19.3 \\
25.2 \\
17.4 \\
22.0 \\
\end{array}$ & $\begin{array}{r}6.3 \\
9.4 \\
21.9 \\
29.1 \\
33.3 \\
\end{array}$ & $\begin{array}{l}208 \\
214 \\
199 \\
138 \\
121 \\
\end{array}$ \\
\hline \multicolumn{2}{|c|}{ Total (percent) } & 100.0 & 100.0 & 100.0 & 100.0 & 100.0 & \\
\hline \multicolumn{2}{|l|}{$N$} & 164 & 182 & 220 & 218 & 96 & 880 \\
\hline
\end{tabular}

Tau $B=0.28$

accommodation to levels of high crime. Thus, many of the blacks who live in areas of high crime are highly satisfied with the safety of their neighborhoods. While 29 percent of blacks residing in areas with the highest crime rates expressed high satisfaction with safety (the two highest categories) less than 16 percent of whites in areas with high crime rates expressed the same level of satisfaction.

In brief, the disaggregation by race encapsulates several variations in the neighborhood characteristics which could affect relationships between objective and subjective measures of safety. Therefore, it might be useful to determine, empirically, the influence of scale discordance for blacks and whites separately. This may give further insights into the influence of scale discordance on two groups which differ not only in social and environmental characteristics, but which apparently differ in terms of the influence that objective conditions have on subjective evaluations of safety.

\section{RACE AND SCALE DISCORDANCE}

When levels of objective crime are considered simultaneously with the three personal variables incorporated into the model discussed earlier, sharp differences emerge between blacks and whites in terms of its' ability to predict satisfaction with safety. As in the earlier analysis, a benchmark is provided for comparing the effects of scale discordance - with the results for the two groups summarized first without taking the neighborhood size factor in to 
account (Table VIII). The eta coefficients ( 0.40 for whites, 0.12 for blacks) provide further evidence of the weaker association between the objective and subjective measures of crime, revealed initially by the Tau B statistic. This difference is reflected in the relative importance of the objective crime variable in the multivariate prediction of satisfaction with safety. The marginal contribution of objective safety for whites raised the explanation of variance in the dependent variable by 11 percentage points, from 6.5 percent to 17.5 percent. For blacks, however, only 3.4 percentage points have been added by incorporating the objective crime data. These differences lend further support to the hypothesis that, compared to whites, blacks are more likely to adjust to high crime environments in which many of them live.

\section{TABLE VIII}

Prediction of satisfaction with safety by personal characteristics and objective crime rates: Whites and blacks (multiple classification analy sis)

\begin{tabular}{|c|c|c|c|}
\hline & \multicolumn{3}{|l|}{ WHITES } \\
\hline & \multirow{2}{*}{$\begin{array}{l}\text { Eta } \\
\text { coefficient }\end{array}$} & \multicolumn{2}{|c|}{ Beta coefficient (ranking of importance) } \\
\hline & & $\begin{array}{l}\text { I } \\
\text { Personal charac- } \\
\text { teristics only }\end{array}$ & $\begin{array}{l}\text { II } \\
\text { Personal charac- } \\
\text { teristics and } \\
\text { objective crime }\end{array}$ \\
\hline $\begin{array}{l}\text { Personal characteristics } \\
\text { Length of residence in city } \\
\text { Age of respondent } \\
\text { Number of years schooling }\end{array}$ & $\begin{array}{l}0.21 \\
0.14 \\
0.14\end{array}$ & $\begin{array}{l}0.22(1) \\
0.14(3) \\
0.17(2)\end{array}$ & $\begin{array}{l}0.10(4) \\
0.11(3) \\
0.15(2)\end{array}$ \\
\hline \multirow[t]{2}{*}{$\begin{array}{l}\text { Objective crime } \\
\text { Index crime rate } \\
\text { Explained variance } \\
\text { (adjusted multiple } R^{2} \text { ) } \\
\text { Number of respondents }=775\end{array}$} & 0.40 & $6.5 \%$ & $\begin{array}{l}0.36(1) \\
17.5 \%\end{array}$ \\
\hline & BLACKS & & \\
\hline $\begin{array}{l}\text { Personal characteristics } \\
\text { Length of residence in city } \\
\text { Age of respondent } \\
\text { Number of years schooling }\end{array}$ & $\begin{array}{l}0.10 \\
0.26 \\
0.26\end{array}$ & $\begin{array}{l}0.13(3) \\
0.29(1) \\
0.24(2)\end{array}$ & $\begin{array}{l}0.13(4) \\
0.33(1) \\
0.24(1)\end{array}$ \\
\hline $\begin{array}{l}\text { Objective crime } \\
\text { Index crime rate } \\
\text { Explained variance } \\
\text { (adjusted multiple } R^{2} \text { ) } \\
\text { Number of respondents }=377\end{array}$ & 0.12 & $7.4 \%$ & $\begin{array}{l}0.21(3) \\
10.8 \%\end{array}$ \\
\hline
\end{tabular}


The summary statistics for the prediction of subjective safety for blacks and whites confirm the influence of scale discordance revealed by the analysis for the total sample (Table IX). To simplify the presentation of results, details for only the large neighborhood groups have been incorporated in Table IX. ${ }^{6}$

Despite the general effect of scale discordance for blacks and whites, disaggregation into large and small neighborhood groups revealed further difference between the two racial groups. For whites, the scale discordance factor increases the proportion of total variance explained by the model. Blacks who view their neighborhoods as relatively large also display a stronger association between objective and subjective crime $($ eta $=0.20)$ than do all

\section{TABLE IX}

Prediction of satisfaction with safety for large neighborhood perceivers: Blacks and whites (multiple classification analysis)

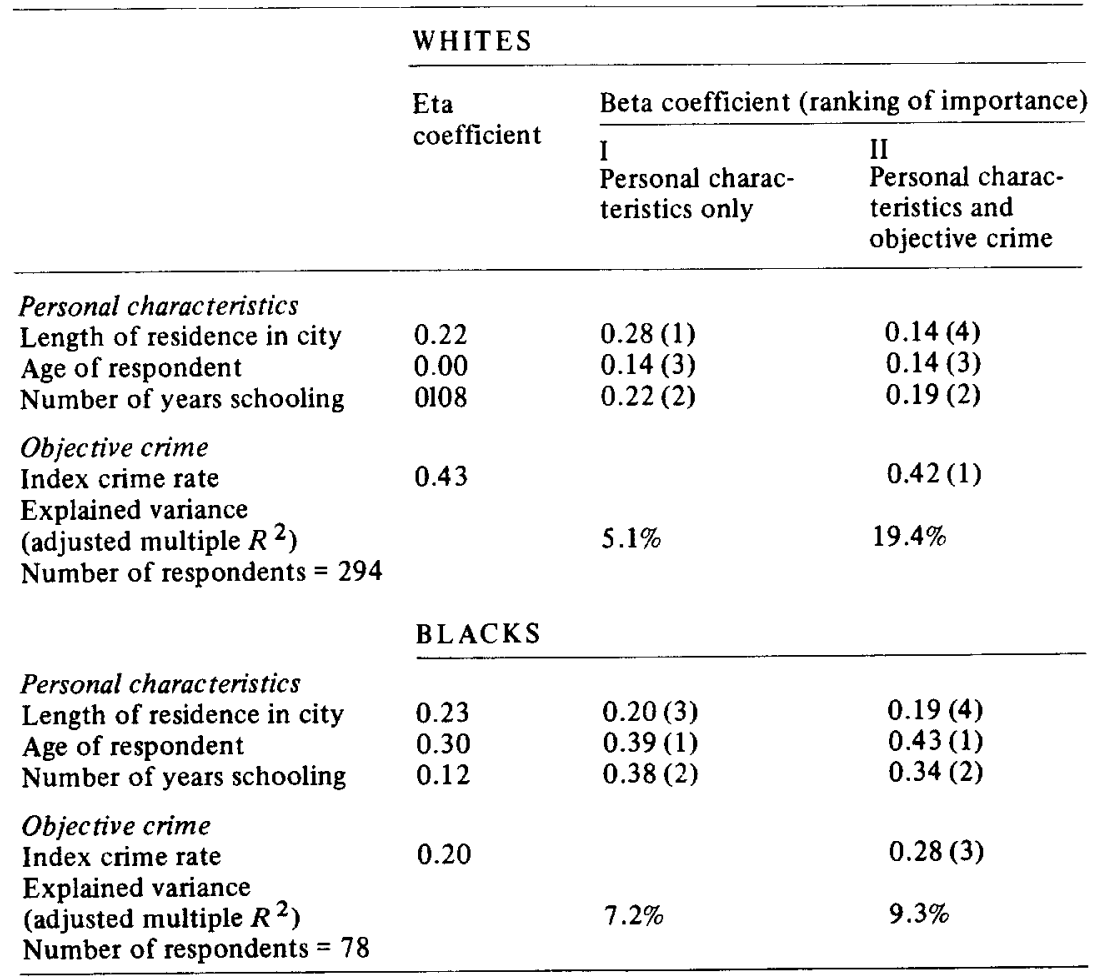


blacks (eta $\mathbf{0 . 1 2}$ ) or blacks who view their neighborhood as a small unit $(\mathrm{eta}=0.04)$. However, the model did not raise the proportion of variance explained for the large neighborhood group above that for all blacks.

The inability of the objective crime variable to raise the explanatory power of the model for blacks who perceive their neighborhood as large, draws attention back to the concept of accommodation. In other words, a possible explanation for the outcome of the model for the large neighborhood black group is that the influence of the objective crime environment is modified by the adjustment of blacks to the high crime environments in which many of them live. By accommodating, or adapting to the prevailing levels of crime around them, other factors may become more critical in determining how people feel about the safety of their neighborhoods.

\section{SUMMARY AND CONCLUSIONS}

Clearly, there are numerous factors - personal, behavioral and environmental - which can affect the objective-subjective relationship of social indicators. It bears repeating that the models used in these analyses have not attempted to account for as much as possible of the variance in feelings of safety. Rather, this paper has focused on the role of scale discordance which can result in a mismatch of the territorial bases upon which objective and subjective evaluations are made.

Scale discordance was hypothesized as one of the many possible variables which modifies relationships between objective conditions and subjective evaluations of the same condition. Using crime data and subjective feelings of safety from a quality of urban life study, it was shown that more of the variance in subjective safety could be explained for respondents who viewed their neighborhood as a large unit, a closer approximation of the size of the territorial base upon which objective data are collected.

To test the resilience of this factor when other intervening variables are considered, the population was disaggregated by race. The effect of perceived size of neighborhood was apparent for both groups, although it was much weaker for blacks than it was for whites. For blacks, the notion of accommodation to the high crime environment in which many of them reside appears to be inextricably interwoven with the scale discordance factor examined here.

The influence of scale discordance gives further insight into the nature 
of factors which can alter relationships between objective conditions and subjective evaluations of the conditions. Universal knowledge and recognition of the complexity and multiplicity of modifying factors is needed in the social indicators by those who would point to the inconsistencies and contradictions between objective and subjective measures as evidence of the irrelevance of one, or both, types of indicators. The discrepancies between objective and subjective indicators do not detract from the value of either - they merely reinforce the need for the parallel development of both sets of indicators.

The implications of these findings have relevance for both research and policy making. For the researcher seeking to explain divergence between objective and subjective indicators, the analyses undertaken here indicate that data analysists should be aware, at least, of the possible influence of scale discordance, and not assume that subjective assessments will be based on the same territorial units as objective indicators. This paper cannot determine how universally relevant scale discordance may be for objective-subjective relationships among different populations and for different conditions, but it would be of value of the social indicators literature to have the concept tested in different contexts.

Policy makers too, need to be aware of the reasons for possible discrepancies between objective and subjective indicators. As Marans and Wellman have pointed out in relation to water quality (1977, p. 250) discrepancies between objective and subjective indicators can lead to either unnecessary concern, or an unwarranted sense of complacency with respect to any specific condition. In either case, misguided programs of management may result. Knowledge of possible reasons for divergence between indicators offering different perspectives of the same domain need to be fully understood if the value of both approaches is to be maximized.

Institute for Social Research, The University of Michigan

NOTES

* The authors wish to acknowledge Frank M. Andrews, Willard Rodgers and Brian Stipak for their helpful comments on an earlier draft of this paper. This research was sponsored by a National Institute of Mental Health Grant No. 1 R01MH29278-01, 'Quality of Life Indicators: Analysis of Detroit Data'. 
1 Objective measures of crime were gathered for police precincts in the City of Detroit and the jurisdictions from which sampled households were located. A composite crime index was used and is reported per 100000 population. A Satisfaction with Safety Index was constructed from each respondent's scores on three satisfaction questions dealing with personal safety, family safety and property safety.

2 Political and administrative units have been the basis for collecting other types of objective indicators in our Detroit quality of life work as well as in other Institute studies.

3 In both models the dependent variable was an Index of Subjective Safety.

4 It should be noted that crime rate alone accounts for 16 percent of variance is subjective safety and the marginal contribution of background characteristics is only 1.5 percent.

5 We recognize that the differences in the measures of association for blacks and whites also may be attributable to the limited or restricted variations in the objective crime measure for the black population.

6 However, for blacks and whites, the predictive ability of the model for the small neighborhood groups was less than that for the large neighborhood group, and less than that for the appropriate racial group as a whole.

\section{B IB LIOG R A PH Y}

Andrews, F. M., James N. Morgan, John N. Jonquist and Laura Klem: 1973, Multiple Classification Analysis (Institute for Social Research, The University of Michigan, Ann Arbor, Michigan).

Andrews, F. M. and S. B. Withey: 1976, Social Indicators of Well-Being: American's Perceptions of Life Quality (New York: Plenum Press).

Appleyard, D. and M. Lintell: 1972, 'The environmental quality of city streets: The residents' viewpoint', American Institute of Planning Journal 38, pp. 84 - 101.

Bradburn, N. M.: 1969, The Structure of Psychological Well-Being (Chicago: Aldine).

Campbell, A., P. E. Converse, and W. L. Rodgers: 1976, The Quality of American Life: Perceptions, Evaluations and Satisfactions (New York: Russell Sage Foundation).

d'Iribarne, P.: 1974, 'The relationships between subjective and objective well-being', in B. Strumpel (ed.) Subjective Elements of Well-Being (Paris: O.E.C.D.).

Flax, M. J.: 1976, A Study in Comparative Urban Indicators: Conditions in 10 Large Metropolitan Areas (Washington, D.C.: The Urban Institute).

Gurin, G., J. Veroff and S. Feld: 1960, Americans View Their Mental Health (New York: Basic Books).

Liu, B-C.: 1975, 'Quality of life: Concept, measurement and results,' The American Journal of Economics and Sociology 34, pp. 1-13.

Liu, B-C.: 1976, Qualitiy of Life Indicators in U.S. Metropolitan Areas: A Statistical Analysis (New York: Praeger Publishers).

Marans, R.W., and J. D. Wellman: 1972, The Quality of Nonmetropolitan Living: Evaluations, Behaviors and Expectations of Northern Michigan Residents (Institute for Social Research, The University of Michigan, Ann Arbor, Michigan).

Marans, R. W., J. D. Wellman, S. J. Newman and J. Kruse: 1976, Waterfront Living: A Report on Permanent and Seasonal Residents in Northern Michigan (Institute for Social Research, The University of Michigan, Ann Arbor, Michigan).

Rodgers, W. L., et al.: 1975, The Quality of Life in the Detroit Metropolitan Area: Frequency Distributions. (Institute for Social Research, The University of Michigan, Ann Arbor, Michigan). 
Schneider, M.: 1975, 'The quality of life in large american cities: Objective and subjective social indicators,' Social Indicators Research 1, pp. 495-509.

Schuman, H. and B. Gruenberg: 1972, 'Dissatisfaction with city services: Is race an important factor?', in H. Hahn (ed.), People and Politics in Urban Society (Beverely Hills, California: Sage Publications).

Stipak, B.: 1977, 'Attitudes and belief systems concerning urban services', The Public Opinion Quarterly 41,pp. 41-55.

Tajfel, H.: 1968, 'Social perception', in D. L. Sills (ed.), International Encyclopedia of the Social Sciences, Vol. II (New York: The Macmillan Company and the Free Press), pp. 567-575. 